\title{
Testing single point incremental forming molds for thermoforming operations
}

Daniel Afonso', Ricardo Alves de Sousa', and Ricardo Torcato'

Citation: AIP Conference Proceedings 1769, 060016 (2016); doi: 10.1063/1.4963452

View online: http://dx.doi.org/10.1063/1.4963452

View Table of Contents: http://aip.scitation.org/toc/apc/1769/1

Published by the American Institute of Physics 


\title{
Testing Single Point Incremental Forming Molds For Thermoforming Operations
}

\author{
Daniel Afonso ${ }^{1,2, a)}$, Ricardo Alves de Sousa ${ }^{1, b)}$ and Ricardo Torcato ${ }^{2,3, c)}$ \\ ${ }^{1}$ TEMA: Centre for Mechanical Technology and Automation, Department of Mechanical Engineering, University of \\ Aveiro, Campus de Santiago 3810-183 Aveiro Portugal \\ ${ }^{2}$ School of Design, Management and Production Technologies Northern Aveiro, University of Aveiro, Estrada do \\ Cercal, 449 3720-509 Santiago de Riba-Ul - Oliveira de Azemis - Portugal \\ ${ }^{3}$ Centre for Research in Ceramic and Composite Materials, CICECO, University of Aveiro \\ ${ }^{a}$ Corresponding author: dan@ua.pt \\ b)rsousa@ua.pt \\ c) ricardo.torcato@ua.pt
}

\begin{abstract}
.
Low pressure polymer processing processes as thermoforming or rotational molding use much simpler molds then high pressure processes like injection. However, despite the low forces involved with the process, molds manufacturing for this operations is still a very material, energy and time consuming operation.

The goal of the research is to develop and validate a method for manufacturing plastically formed sheets metal molds by single point incremental forming (SPIF) operation for thermoforming operation. Stewart platform based SPIF machines allow the forming of thick metal sheets, granting the required structural stiffness for the mold surface, and keeping the short lead time manufacture and low thermal inertia.
\end{abstract}

\section{INTRODUCTION}

The thermoforming processes, namely vacuum forming, allows the production of plastic parts by shaping a polymer sheet or film to a mold. Despite using a much simpler mold than other polymer processing technologies as injection, mold cost and development time still has a considerable weight in the development of a product. As thermoforming pressure is low, it is possible to replace conventional mold materials and designs by sheet metal based molds. Single Point Incremental Forming (SPIF) can be used to shape sheet metal to the desired surface.

Most thermoforming molds are single surfaced. One surface of the plastic sheet if forced against the mold and the other surface remains unimpeded. Both positive and negative molds can be use in vacuum thermoforming operations. The negative or female mold uses a cavity with the complementary geometry of the outside of the plastic part. It is used when the outside of the plastic part is to be controlled. As the SPIF process produces cavities, the definition of the geometry to be formed is straightforward as thickness reduction on the formed metal sheet doesn't affect inner dimension. The positive or male mold uses a boss with the complementary geometry of the inside of the plastic part. It is used when the inside of the plastic part is to be controlled. Whereby the SPIF operation controls the inner surface of the sheet and causes a thickness reduction, the definition of the mold geometry it is much devious.

Thermoforming sheet metal molds made by SPIF operations have been tested by Appermont et al [1]. Due to SPIF process limitation, the molds need to be supported to prevent unwanted deformation. A porous mixture of expanded clay grains and resin was used and shown to have a good behaviour.

Using the Stewart platform based SPIF machine developed at Universidade de Aveiro [2] strength related issues are avoided thus enabling the manufacture of thicker sheet metal molds. For concept validation a part with only one plane of symmetry was design to be thermoformed in both on a positive and a negative mold. The test part was design as a 5 sides box with a minimum draft angle of 20 used on the higher slant sides and one side with a smaller slide. Flat areas were used to allow the cutting of type IV specimens [3] for mechanical comparative test. 


\section{SPIF SHEET METAL MOLDS}

Single point Incremental forming is an operation made by a CNC controlled tool fallowing a toolpath a forming a sheet to the desired shape without dedicated punches or dies. For better definition of the formed part border, a backing plate can be used to help supporting the sheet on flat areas. On SPIF operation the metal sheet is clamped on a frame. The surface shaping result from the plastic stretch. This change on the state of material causes a thinning of the sheet greater has higher is the strech. Figure 1 represents the sheet thinning on SPIF operations.

One can estimate the final thickness using the sine-law (eq. 1), where $\alpha$ is the angle between the horizontal and final geometry. This fact is mostly true when operating with single passage toolpath strategies. Thus, to propose a design for a SPIF sheet positive mold a single step toolpath in better suited leading to limited maximum angle. On negative molds the number of passages on the toolpath is not as restrictive.

$$
t_{f}=t_{i} \cdot \sin (90-\alpha)
$$

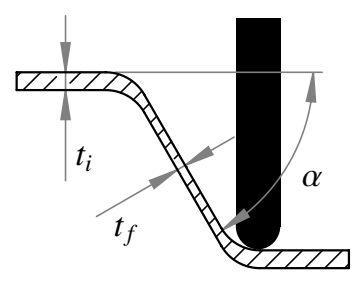

FIGURE 1. SPIF process with sheet thickness variation in single step operation

\section{Mold Design}

The test part was designed as a single symmetric part with a projected area of $180 \mathrm{~mm}$ by $180 \mathrm{~mm}$, a maximum height of $66 \mathrm{~mm}$ and a constant thickness of $3 \mathrm{~mm}$. It was shaped as a 5 sides box with a minimum draft angle of 20 used on the higher slant sides and one side with a smaller slide. The internal radius used between side faces was $15 \mathrm{~mm}$ and between side and top faces was $6 \mathrm{~mm}$. The top has a $120 \mathrm{~mm}$ by $35 \mathrm{~mm}$ flat area and the smaller slope side has a $127,6 \mathrm{~mm}$ by $106,6 \mathrm{~mm}$ flat area to cut specimens.

An Aluminium Alloy 1050 formed sheet based molds were designed. Negative mold was shaped by the complementary surface of the outer side of the test part. This result on a $180 \mathrm{~mm}$ by $180 \mathrm{~mm}$ cavity on the mold. Positive mold was shaped by expanding the complementary surface of the inner side off the test par, getting to a $180 \mathrm{~mm}$ by $177 \mathrm{~mm}$ boss on the mold. Figure 2 represents the concept design method used for both negative and positive with same width, in order to use the same backing plate.

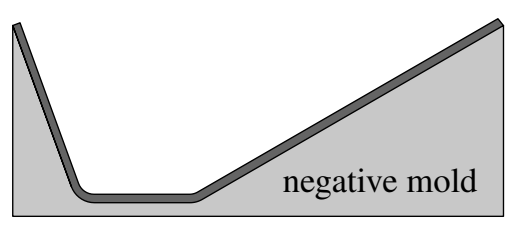

(a)

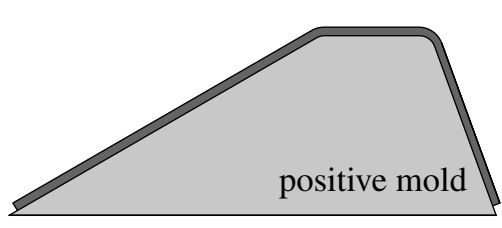

(b)

FIGURE 2. Thermoforming mold concept: (a) negative mold with same width as test part, (b) positive mold with extended surface to equal negative mold width

Sheet metal molds were design with a similar approach to the one fallowed by Appermont et al. [1]. A SPIF sheet shapes the mold surface and it is supported by a MDF box. For both positive and negative molds a similar approach was taken, using $230 \mathrm{~mm}$ square sheet supported by a 20 draft box. However, instead adding a grid of support points or lines or filling the mold box with a porous mixture to increase the stiffness of the mold, a thicker sheet was used. 
Finite element method was used to determine minimum sheet thickness. Simulation was done with AA1050 $\mathrm{H} 111$ formed sheet resting on a $16 \mathrm{~mm}$ MDF board on the positive mold and resting on a MDF box on the negative mold. For the CAD model, sheet thickness on mold walls was determined by the sine law (1). Simulation was done considering the base fixed and a uniform pressure of $0,1 \mathrm{MPa}$ on all outer surfaces. Global contact between parts was defined with no penetration and a static frictional coefficient of 0,2 between parts. A $3 \mathrm{~mm}$ sheet was chosen for mold manufacturing.

\section{Mold Manufacture}

The manufacturing of a mold by single point incremental forming starts with the cut of a backing plate. The drawing of the backing plate is made by offsetting the outline of the sheet part by $1 \mathrm{~mm}$. A waterjet cutting process was used in order to cut the backing plate from a $5 \mathrm{~mm}$ steel sheet. The same backing plate was used for both positive and negative mold. Second step of the process involves the cut of the aluminium sheet. The $230 \mathrm{~mm}$ by $230 \mathrm{~mm} 3 \mathrm{~mm}$ thickness blank was cut from an flat aluminium sheet using an hydraulic guillotine. 2 blanks were cut to be used in each mold.

For the SPIF operation, a spiral constant $Z$ toolpath with a vertical increment of $0,5 \mathrm{~mm}$ using a $12 \mathrm{~mm}$ ball tip tool was programed. The toolpath was post process to run on the SPIF machine. SPIF machine set up includes changing backing plate, changing tool and changing sheet holders. Blank was then holded to the frame and referenced and forming process ran at $3000 \mathrm{~mm} / \mathrm{min}$ feed rate. Figure 3 (a) illustrates one of the final $\mathrm{z}$ increments of the negative mold SPIF operation.

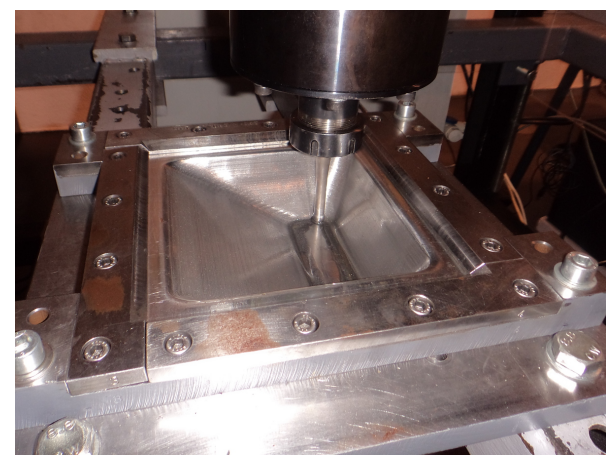

(a)

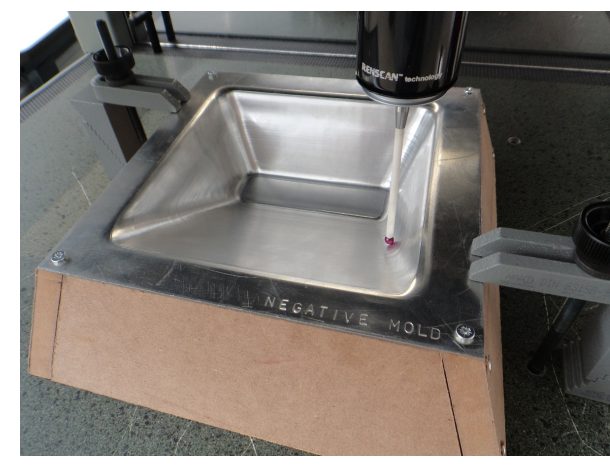

(b)

FIGURE 3. Negative mold fabrication and measurement: (a) SPIF operation forming negative sheet metal molds; (b) CMM touchtrigger probe measuring mold

After forming operation, the base MDF board for the positive mold and MDF box for the negative bold were made to assembly the molds. Angle cuts were made with a circular saw and parts assembled with self tapping screws. Sheet molds were drilled for vacuum suction of the plastic sheet and then screwed to the MDF to be hold on place. The manufacture time consuming was measured. Total fabrication time for the positive mold was $1 h 10 \mathrm{~min}$ being only $57 \%$ for SPIF process. The negative mold fabrication time was $1 \mathrm{~h} 28 \mathrm{~min}$ with only $45 \%$ of the time for SPIF process. SPIF sheet molds were measured by contact using a touch-trigger probe on a 3 axis co-ordinate measuring machines (CMM). Figure 3 (b) illustrates the measuring operation of the negative sheet metal mold. Maximum deviation was $2.9 \mathrm{~mm}$ on the positive mold and $6.8 \mathrm{~mm}$ ou the negative mold. Average deviation was $0.3 \mathrm{~mm}$ on the positive mold and $1.7 \mathrm{~mm}$ ou the negative mold.

\section{Thermoforming With Sheet Metal Molds}

For mold validation, a 3mm PMMA (acrylic) sheet sheet was used for thermoforming operation. Experiment took place on a Formech 1772 machine with $100 \mathrm{sec}$ of heat time at $100 \%$ power on one side of the sheet and $200 \mathrm{sec}$ on the other. Vacuum was hold for $15 \mathrm{sec}$ and cooling by air blowing was hold for $30 \mathrm{sec}$. Figure 4 (a) illustrates the thermoforming process on the negative mold. Parts were first validated by a visual inspection and then cut by mold plane edges as shown on the part formed on the positive mold in fig. 4 (b). 


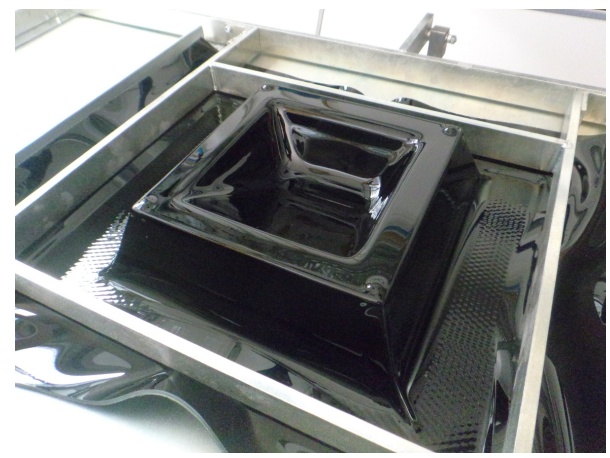

(a)

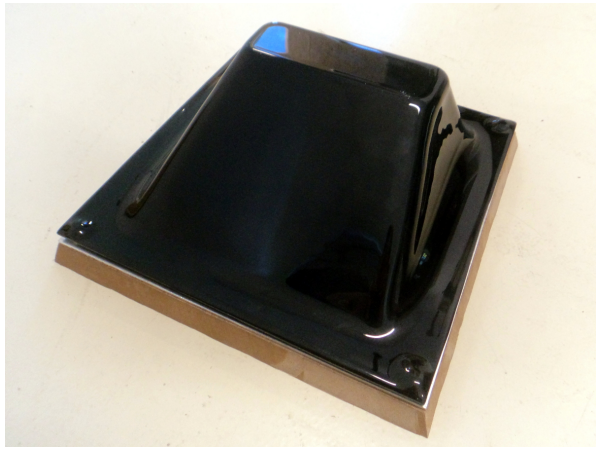

(b)

FIGURE 4. Thermoforming with SPIF sheet metal molds: (a) negative mold on thermoforming machine during vacuum; (b) thermoformed part after trimming over the positive mold

For dimensional control, thermoformed parts were measured by contact on a CMM. On each part, the surface in contact with the mold was measured. On the part formed on the positive mold, maximum deviation between formed part and CAD model was $14.7 \mathrm{~mm}$ with an average of $0.7 \mathrm{~mm}$. On the part formed on the negative mold, maximum deviation was $11.4 \mathrm{~mm}$ with an average of $1.8 \mathrm{~mm}$. When comparing parts to the real mold geometry, maximum deviation was $5.8 \mathrm{~mm}$ on the positive and $10.6 \mathrm{~mm}$ on the negative with respective average of $0.1 \mathrm{~mm}$ and $0.2 \mathrm{~mm}$.

Furthermore, both molds were remeasured after being used to check for permanent deformations caused due to vacuum. No major variations were found with average $0.05 \mathrm{~mm}$ between first measurement and the one done after use.

\section{CONCLUSION AND FUTURE WORK}

Sheet metal molds made by SPIF are a reliable alternative to the conventional molds. Despite some significant deviations still occur at some points, general appearance of plastic parts reasonably good and average dimension is accurate. Mould total manufacture time and cost are low yet largely influenced by some parallel operations. As accessories like backing plate for SPIF operation and MDF support boxes can be used for more then one mold with similar projected area, the use of sheet metal moulds assumes even a more interesting panorama.

To determine the process accuracy, future works involves improvements on the SPIF strategy for mold manufacture and the manufacture of a small series of parts for measurement control and for mechanical test of cut specimens from top and smaller slope sides. Acquired data can be compared with equivalent tests performed on parts thermoformed on a conventional molds.

\section{REFERENCES}

[1] R. Appermont, B. Van Mieghem, A. Van Bael, J. Bens, J. Ivens, H. Vanhove, A.K. Behera, and J. Duflou, "Sheet-metal based molds for low-pressure processing of thermoplastics," in Proceedings of the 5th Bi-Annual PMI Conference, pages 383-388, 2012.

[2] S. Marabuto, D. Afonso, J. Ferreira, F. Melo, M.A. Martins, and R. de Sousa, "Finding the best machine for spif operations-a brief discussion," in Key Engineering Materials, pages 861-868, 2011.

[3] "Standard test method for tensile properties of plastics," ASTM, West Conshohocken, PA, 2010.

[4] James L. Throne, "Thermoforming 101," SPE thermoforming division, 2006.

[5] GE plastics, "Thermoforming Processing Guide," GE Engineering Thermoplastics Processing Guide. 